\title{
Retrospective Evaluation of Outcome of Rerouting Technique in Management of Horseshoe Perianal Fistula, Single Institution Experience
}

YASSER M. ABDEL-SAMIA, M.D.; IBRAHIM M. ABDEL-MAKSOUD, M.D. and SALEM A. FAGR, M.Sc. The Department of General Surgery, Faculty of Medicine, Ain Shams University

\begin{abstract}
Background: Complex anal fistula is a topic of debate from ancient times due to its difficult treatment and its effect on patients quality of life. The most complex anal fistula is the branched transsphincteric fistula with secondary extension in the perianal spaces forming the configuration U-shaped or horseshoe fistula. Many surgical technique have been described for treatment of this fistula as fistulotomy as was described by Hanly 1965 but he noted high risk of anal incontinence despite the complete eradication of the deep post anal sepsis.
\end{abstract}

Aim of Study: To evaluate retrospectively patients with complex horseshoe fistula for them re-routing technique was done with respect to operative time, occurrence of incontinence and rate of recurrence of the fistula.

Patients and Methods: This study is a retrospective observational study that was conducted on 30 patients who had complex horseshoe perianal fistula and underwent re-routing technique for the fistula in the last 3 years; from January 2017 to December 2019. Follow-up of the patients was for 6 months. They were recruited from General Surgery Department, Ain Shams University Hospitals (El-Demerdash), Ain Shams University, Egypt.

Results: Of the 30 patients, 27 patients (90\%) preserved complete and full continence. Only 3 patients (10\%) developed incontinence post-operatively after the second stage, stage of rerouting. Of the 3 patients developed incontinence, 2 patients $(6.7 \%)$ developed only gas incontinence which is according to wexner scoring system was "sometimes" that occurred less than once per week and only 1 patient (3.3\%) developed gas and liquid stool incontinence which according to the wexner score system was "rare" that occurred less than once per month. All 3 cases developed incontinence didn't need to wear pads and there was no effect on their life style. After 6 months follow-up of the patients, recurrence occurred only in 2 patients $(6.7 \%)$ at 3.5 and 5 months which was not statistically significant.

Conclusion: Rerouting technique is a suitable proper sphincter preserving procedure for the management of the complex horse shoe perianal fistula with low recurrence rate, very acceptable and satisfactory magnitude of preservation of anal continence with no effect on patient's quality of life.

Correspondence to: Dr. Salem A. Fagr, E-Mail: Salem2020surgery@yahoo.com
Key Words: Horseshoe perianal fistula - Rerouting.

\section{Introduction}

A FISTULA is typically defined as an abnormal communication between 2 epithelialized surfaces. Anal fistulae manifest as an abnormal communication between the anorectal canal and perianal skin. Anal fistula is a common anorectal disorder that is treated surgically. Anal fistula poses a challenge to the treating surgeon since ancient times [1]. Most fistulas are thought to arise as a result of cryptoglandular infection with resultant peri rectal abscess. The abscess represents the acute inflammatory event, whereas the fistula is representative of the chronic process. However, secondary fistulas may develop due to underlying diseases such as Crohn's disease. If the anorectal abscess is not drained spontaneously or surgically, the infection may spread rapidly and may result in extensive tissue loss. Even if the abscess is drained, anal fistula may develop subsequently [2]

The mean age for presentation of anal abscess and fistula disease is 40 years (range 20 to 60). Adult males are twice as likely to develop an abscess and/or fistula compared with women [3].

Different classifications have been put forward which categorize these Fistula into low or high simple or complex, or according to their anatomy into intersphincteric, trans-sphincteric, and suprasphincteric or extra-sphincteric [4]. However, the most widely used and accepted method is the Park's classification. This system is based primarily on the relationship between the tract to the external sphincter and puborectalis muscles, and included 4 major types; inter sphincteric fistulae, transsphincteric fistulae, supra sphincteric fistulae and extra sphincteric fistulae. These groups can be further 
subdivided according to the presence and courses of associated secondary tracts [5]

Complex fistulas include high transsphincteric (>30\% external sphincter involvement), suprasphincteric, or extrasphincteric fistulae. They may also be defined as horseshoe and may also present with multiple tracts. In Horseshoe fistulae, the fistula tract travels across the body and may have one or multiple openings on either side of the anus [6]. Diagnosis of perianal fistulae is done by clinical examination and/or investigastions. A proper clinical history for anal fistulae is particularly important, as previous or recurrent episodes of perianal abscesses. The history might alert the physician of an underlying pathology (for example, inflammatory bowel disease, malignancy, or chronic infection). On physical examination, the presence of an active infection is usually easily identified by purulent discharge or tenderness following palpation of the external opening. In order to determine the appropriate treatment course, proper mapping of the fistula including locating the internal opening are of utmost importance. Goodsall's rule is an excellent tool for determining the location of the internal opening of the fistula, which uses the site of the external opening as a guide: An external opening located posterior to the midsagittal line will likely have a tract with an internal opening posterior to the midline; conversely, an anterior external opening will travel in a relatively straight line to its internal opening [7].

Investigastions for diagnosis of perianal fistula include conventional fistulogram, CT fistulography, Endoanal ultrasound, MRI and Anorectalmanometry. The conventional fistulogram is a technique in which a water soluble dye is injected into the external fistula opening, and the fistula tract is resolved on X-ray. Computed Tomographic (CT) fistulography is capable of accurately mapping the fistula tract, and provides critical informations that can guide the surgical management of these patients [8]. Endoanal ultrasound, which can be combined with hydrogen peroxide injections into the fistula tract, can provide highly accurate representations of the fistula. The MRI is the gold standard for visualizing anal fistulae. This technique permits the orthogonal visualization of sphincter muscles and mapping of complex and branching fistulae, all of which can easily be identified due to good contrast resolution [9].

Surgical strategies to treat anal fistula tend to be guided by their degree of complexity and their underlying aetiology. For simple low fistula, fistulotomy and lay open may be enough. But for high anal fistula, setonfistulotomy provides good results. Fistulectomy by core out technique is suitable for high anal fistula but not for recurrent or more complex fistula.

Regarding complex fistulas, a clinical consensus about the best operation is still lacking. No single technique has been shown to be suitable for all cases. Furthermore, recurrence rates after surgery seem to be high although studies with proper follow-up are scarce. Therefore, complex anal fistulas management remains a challenge for surgeons worldwide [10]. The Ligation of the Intersphincteric Fistula Tract (LIFT) procedure has been described as the most recent innovation to sphincterpreserving surgery for the management of complex anal fistulas. It was first reported by Rojanasakul et al. in 2007 as a sphincter-preserving procedure, primarily indicated for transsphincteric fistulas [11].

A transposition technique for the management of high anal and anorectal fistulae is described by Mann and Clifton in 1985. The method involves re-routing the extrasphincteric portion of the track into an intersphincteric position with immediate repair of the external sphincter. The newly positioned intersphincteric fistula is then dealt with at a later date when the external sphincter is soundly healed [12].

\section{Aim of the work:}

To evaluate retrospectively patients with complex horseshoe fistula for them re-routing technique was done with respect to operative time, occurrence of incontinence and rate of recurrence of the fistula.

\section{Patients and Methods}

This study is a retrospective observational study that was conducted on 30 patients who had complex horseshoe perianal fistula and underwent re-routing technique for the fistula in the last 3 years; from January 2017 to December 2019. Follow-up of the patients was for 6 months. They were recruited from General Surgery Department, Ain Shams University Hospitals (El-Demerdash), Ain Shams University, Egypt. This study is of single institution experience.

Patients who met the following criteria were enrolled in the study: Complex horseshoe perianl fistula which includes all fistulae with single or multiple tracts with single or multiple external openings in which the deep postanal space affection is demonstrated by bidigital examination and/or preoperative MRI, age ranged from 18-60 and patients from both genders. 

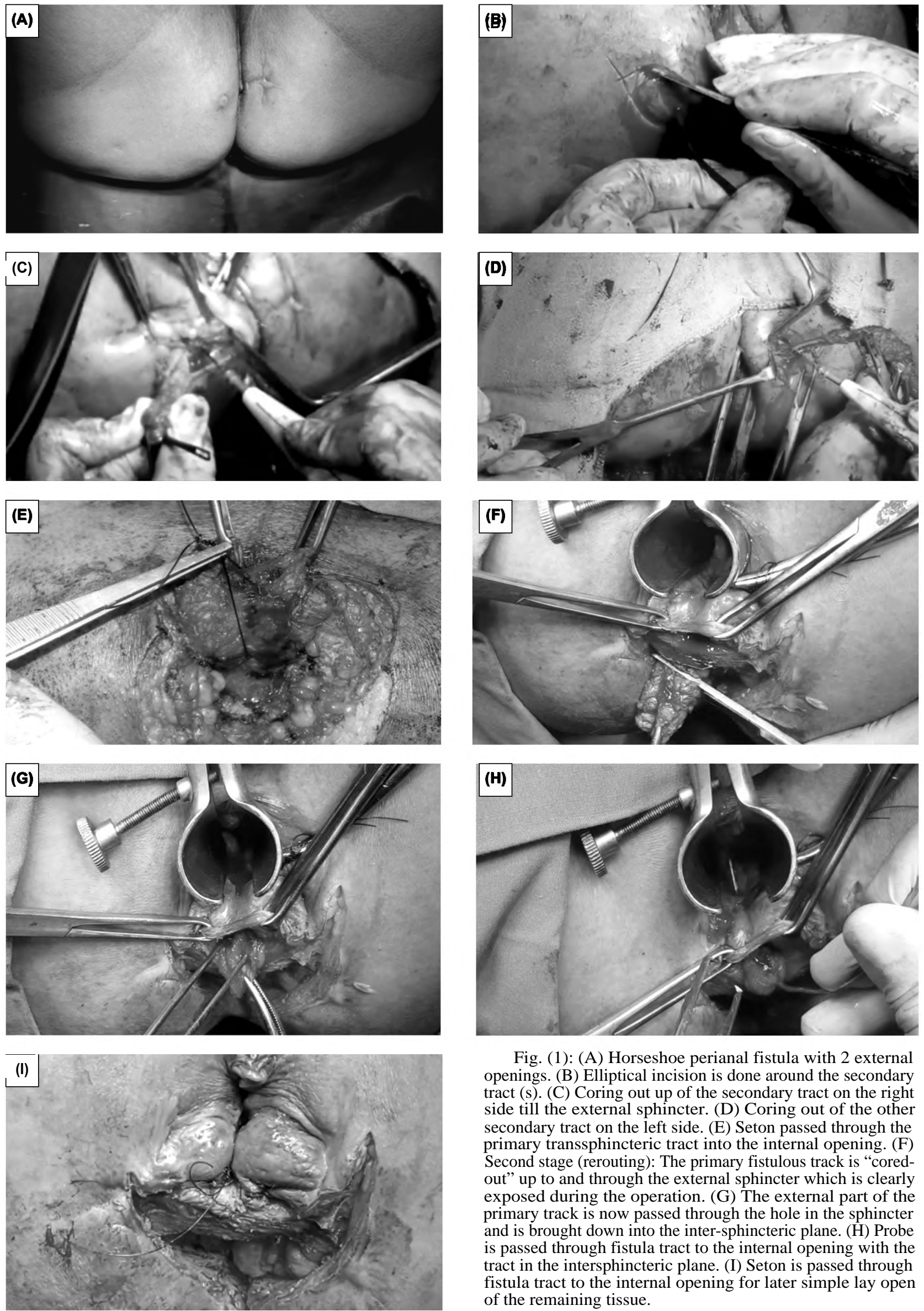

Fig. (1): (A) Horseshoe perianal fistula with 2 external openings. (B) Elliptical incision is done around the secondary tract (s). (C) Coring out up of the secondary tract on the right side till the external sphincter. (D) Coring out of the other secondary tract on the left side. (E) Seton passed through the primary transsphincteric tract into the internal opening. (F) Second stage (rerouting): The primary fistulous track is "coredout" up to and through the external sphincter which is clearly exposed during the operation. (G) The external part of the primary track is now passed through the hole in the sphincter and is brought down into the inter-sphincteric plane. (H) Probe is passed through fistula tract to the internal opening with the tract in the intersphincteric plane. (I) Seton is passed through fistula tract to the internal opening for later simple lay open of the remaining tissue. 
Patients were excluded according to the following criteria: Low, simple and superficial fistula, acute anorectal sepsis, fistula secondary to other pathology (e.g. Malignancy, IBD, trauma, radiation, etc.), associated anorectal conditions as hemorrhoids, anal fissure, rectal prolapse or malignancy, history of previous surgical treatment of anal fistula, and symptomatic pre-operative fecal incontinence.

All patients recruited in the study were subjected to pre-operative work up: History: (Personal history, history of present illness, past history of medical diseases, surgical history), clinical examination (inspection \& digital rectal examination). The site of the internal opening may be evaluated using Goodsall's rule which uses the site of the external opening to detect the site of the internal opening. The degree of continence is evaluated by The Wexner scoring system.

\section{Investigations:}

Routine pre-operative investigations are requested for all patients, including complete blood picture, coagulation profile [Prothrombin Time (PT), Prothrombin Concentration (PC) and International Normalised Ratio (INR)], liver and kidney function tests, fasting blood sugar, chest X-ray. MRI (Magnetic Resonance Imaging) for pelvic or anorectal region: Was done for some patients who were difficult to be diagnosed clinically.

\section{Operative technique:}

Anesthesia: General or spinal anesthesia. Position: Prone jack knife or Lithotomy position. 500mg of metronidazole with $1.5 \mathrm{gm}$ of cefuroxime given intravenously at the beginning of surgery. Antisepsis of the site of the operation. Digital rectal examination and probing to detect the site of the internal opening. This is helped by using proctoscopy and injection of diluted hydrogen peroxide into the external opening and observing its efflux from the internal opening and the other contralateral external opening if present. Inserting probes helps mapping of the fistula with its primary tract and the secondary branched tracts which produces the configuration of horseshoe. The skin around the external opening or openings is ellipticaly incised and the fistulous secondary tracts are dissected as high as possible. Then the fistula secondary tracrt or tracts is "cored out" up to the external sphincter till the origin of these tracts as secondary branches from the primary transphincteric tract. Hereupon, fistulectomy of the secondary tracts is done. If there is any extensions upwards above the levators, it should be laid open. Probe is inserted into the primary tract till the internal opening then marking of the tract using silk suture material as a seton.
After 4 to 5 weeks when complete healing of the external wounds occurs, a second stage is done which includes rerouting of the extrasphincteric part of the primary tract into an intersphincteric part by bringing it down into the intersphincteric plane through a hole in the external sphincter with primary repair of the external sphincter. Seton is inserted into the tract till the internal opening. Here, the complex transphincteric tract becomes simple intersphincteric tract and the wound is left to heal. In the third stage after another 4 to 5 weeks when the external wound is healed, the remaining fistulous track marked by silk suture material is excised or laid open by dividing the remaining tissues. Patients were assessed post-operatively as regards: Operative time, degree of continence by Wexner scoring system and recurrence. Follow-up and evaluation of outcomes at hospital and by telephone, 2 weeks, 1 month, 3 months, and 6 months.

\section{Results}

Table (1): Distribution of the studied cases according to demographic data

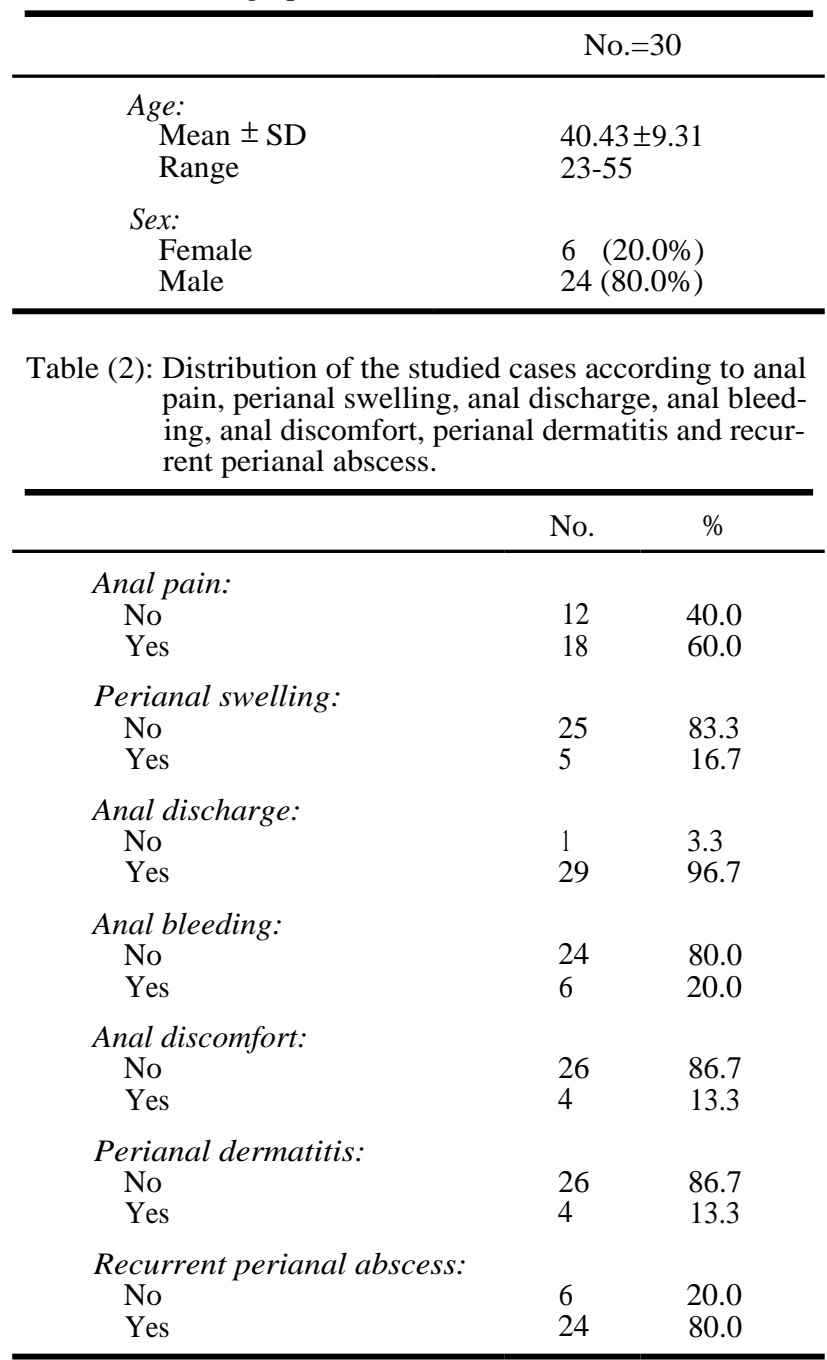


Table (3): Distribution of the studied cases according to diagnosis (only clinical), diagnosis (M.R.I).

\begin{tabular}{lcc}
\hline & No. & $\%$ \\
\hline Diagnosis (only clinical): & & \\
No & 17 & 56.7 \\
Yes & 13 & 43.3 \\
Diagnosis (M.R.I): & & \\
No & 13 & 43.3 \\
Yes & 17 & 56.7 \\
\hline
\end{tabular}

Table (4): Distribution of the studied cases according to [operative time, stage one (min)], [operative time, stage two, stage of rerouting ( $\mathrm{min})$ ] and [operative time, stage three $(\mathrm{min})]$.

\begin{tabular}{ll}
\hline & No. $=30$ \\
\hline Operative time, stage one (min): & \\
Mean \pm SD & $39.33 \pm 8.58$ \\
Range & $25-55$ \\
Operative time, stage two, & \\
stage of rerouting (min): & $51.83 \pm 8.15$ \\
$\quad$ Mean \pm SD & $35-65$ \\
$\quad$ Range & \\
Operative time, stage three (min): & $10.50 \pm 1.72$ \\
Mean \pm SD & $7-15$ \\
Range & \\
\hline
\end{tabular}

Table (5): Distribution of the studied cases according to occurrence of incontinence.

\begin{tabular}{lll}
\hline Incontinence & No. & $\%$ \\
\hline No & 27 & 90 \\
Yes & 3 & 10 \\
\hline
\end{tabular}

Table (6): Distribution of the studied cases according to Gas incontinence and Stool incontinence.

\begin{tabular}{lll}
\hline & No. & $\%$ \\
\hline Gas incontinence: & & \\
No & 28 & 93.3 \\
Yes & 2 & 6.7 \\
Stool incontinence: & & \\
No & 29 & 96.7 \\
Yes & 1 & 3.3 \\
\hline
\end{tabular}

Table (7): Distribution of the studied cases according to Gas incontinence according to Wexner scoring system, type of stool incontinence, degree of stool incontinence according to Wexner scoring system and recurrence.

\begin{tabular}{lll}
\hline & No. & $\%$ \\
\hline $\begin{array}{l}\text { Degree of Gas incontinence: } \\
\text { Sometimes incontinence } \\
\quad(<1 / \text { week } \geq 1 / \text { month) }\end{array}$ & 2 & 100 \\
$\quad \begin{array}{l}\text { Type of incontinence: } \\
\text { Liquid }\end{array}$ & & \\
$\quad$ Solid & 1 & 100 \\
$\quad$ Degree of stool incontinence: & 0 & 0 \\
$\quad$ Rarely incontinence (<1/month) & 1 & \\
Recurrence: & & \\
$\quad$ No & 28 & 93.3 \\
$\quad$ Yes & 2 & 6.7 \\
\hline
\end{tabular}

\section{Discussion}

In this thesis, we evaluated the outcome of rerouting technique as a recent sphincter preserving method for management of complex horse shoe perianal fistula.

Our study is a retrospective study on 30 patients underwent re-routing of the horseshoe fistula tract in the period from January 2017 to December 2019 with follow-up of the patients for 6 months postoperatively in the hospital and by telephone.

Of the 30 patients, 27 patients $(90 \%)$ preserved complete and full continence. Only 3 patients (10\%) developed incontinence post-operatively after the second stage, stage of rerouting. Of the 3 patients developed incontinence, 2 patients $(6.7 \%)$ developed only gas incontinence which is according to wexner scoring system was "sometimes" that occurred less than once per week and only 1 patient $(3.3 \%)$ developed gas and liquid stool incontinence which according to the wexner score system was "rare" that occurred less than once per month. All 3 cases developed incontinence didn't need to wear pads and there was no effect on their life style.

After 6 months follow-up of the patients, recurrence occurred only in 2 patients $(6.7 \%)$ at 3.5 and 5 months which was not statistically significant.

In our study, the average operative time (in minutes) was (39.33 \pm 8.58$)$ with range (25-55) for the first stage, $(51.83 \pm 8.15)$ with range $(35-65)$ for the second stage and $(10.50 \pm 1.72)$ with range (7-15) for the third stage.

To our knowledge, our study is the first study performed describing the results of re-routing technique in the treatment of horseshoe perianal fistula. We found no studies so far describing the results of rerouting technique in treatment of horseshoe anal fistula. All previous rare studies described rerouting technique in treatment of high transsphincteric fistula but with no horseshoe tracts.

Comparing to the literature regarding the rerouting technique, it was found that the procedure described by Mann and Clifton in 1985, performing the rerouting technique on 5 patients with healing rate $100 \%$ and no recurrences with follow-up reaching up to 3 years [12].

Another paper describing 14 patients with high anal fistulae were treated at Basrah General Hospital from 1992 to 2000 by re-routing of the track and the external opening to the anal canal. All patients had satisfactory results, with a period of follow-up ranging from 10 to 91 months, no recur- 
rence of fistulae or abscess formation. Healing was rapid, short hospital stay and continence to flatus and faeces preserved [13].

Abu zeid et al., in comparative study of rerouting technique with ligation of intersphincteric fistula tract for high transsphincteric anal fistula revealed that out of 30 patients concluded in the study who underwent rerouting after 1 year of follow-up, the recurrence rate was $10 \%$ with no incontinence [14].

Our results are in concordance with the findings reported.

The limitations of this study include its retrospective design, the small number of cases concluded in the study and the short period of followup keeping in mind that we do not have clear data about the expected time of recurrence in the procedure. Van der hagen reported that recurrences still occur many years after initial healing [15].

The presence of larger number of cases with longer period of follow-up makes the results more dependable.

\section{Conclusion:}

Rerouting technique is a suitable proper sphincter preserving procedure for the management of the complex horse shoe perianal fistula with low recurrence rate, very acceptable and satisfactory magnitude of preservation of anal continence with no effect on patient's quality of life.

\section{References}

1- SNEIDER E. and MAYKEL J.: Anal Abscess and Fistula. Gastroenterol. Clin. North Am., 42: 773-84, 2013.

2- POGGIO J.: Fistula InAno. Medscape, Http://Emedicine. Medscape. Com/Article/190234, 2015.

3- BREEN E. and BLEDAY R.: Anorectal fistula: Clinical manifestations, diagnosis, and management principles. Uptodate, 2015.
4- PANIGRAHI H., RAKESH R., PADHI M. and LAVEKAR G.: Clinical Evaluation of Kshara Sutra Therapy In The Management of Bhagandara (Fistula- InAno)- A Prospectivestudy. Ancient Science of Life, 28 (3): 29-35, 2009.

5- NICHOLLS R.: Fistula In Ano: An Overview. Acta ChirIugos, 59: 9-13, 2012.

6- ABOULIAN A., KAJI A.H. and KUMAR R.R.: Early result of ligation of the intersphincteric fistula tract for fistula-in-ano. Diseases of the Colon \& Rectum, 54 (3): 289-92, 2011

7- SIMPSON J., BANERJEA A. and SCHOLEFIELD J.: Management Of Anal Fistula. BMJ, 345: 6705, 2012.

8- LIANG C., JIANG W., ZHAO B., ZHANG Y., DU Y. and LU Y.: Ct Imaging With Fistulography For Perianal Fistula: Does It Really Help The Surgeon? Clin. Imaging, 37: 1069-76, 2013.

9- KHERA P., BADAWI H. and AFIFI A.: MRI. In Perianal Fistulae. Indian J. Radiol Imaging, 20: 53-7, 2010.

10- CAMPBELL M.L., ABBOUD E., DOLBERG M., et al.: Treatment of Refractory Perianal Fistulas with Ligation of the Intersphincteric Fistula Tract: Preliminary Results. Am. Surg., 79: 723-7, 2013.

11- CHRISTOFORIDIS D., ETZIONI D., GOLDBERG S., et al.: Treatment of Complex Anal Fistulas with the Collagen Fistula Plug. Dis. Colon. Rectum., 51: 1482-7, 2008.

12- MANN C.V. and CLIFTON M.A.: Rerouting of the track for the treatment of high anal and anorectal fistulae. Br. J. Surg., 72: 134-7, 1985.

13- KHAYAT H. and AL-HAWAZ M.: Re-routing in high anal fistula. Basrah J. of Surgery, 7: 127, 2001.

14- ABOU-ZEID AHMED A., TAREK Y. AHMED, ESSAM F. EBIED, AHMED A. DARWEESH, AHMED A.KHALIL, TASNIM R. NAEEM, et al.: Comparative Study between Re-Routing Technique and Ligation of Intersphincteric Fistula Tract (LIFT) In Treatment of High Perianal Fistula. Nature and Science, 17 (10), 2019.

15- VAN DER HAGEN S.J., BAETEN C.G., SOETERS P.B., et al.: Staged mucosal advancement flap versus staged fibrin sealant in the treatment of complex perianal fistulas. Gastroenterol. Res. Pract., 186350, 2011. 


\section{تقييم نتائج تقنية إعادة التوجيه

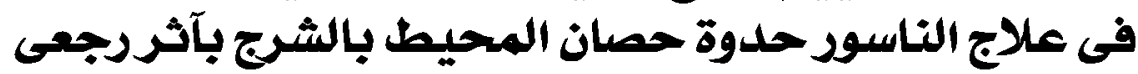 \\ فى تجرية مؤسسة واحندة الهرة}

إن الناسود الشرجى المعقد لموضوع جدلى منذ قدم العصود ويرجع ذلك إلى صعوبة علاجه وتآثيره على طبيعة حياة المريض . الناسود

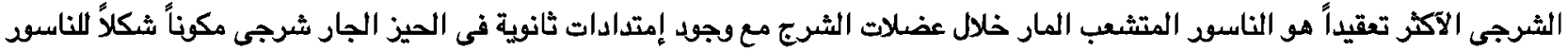

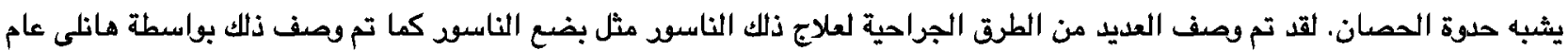

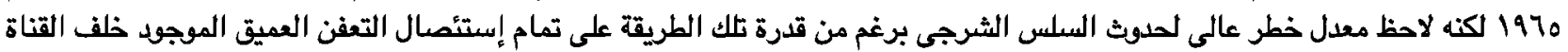

في هذه الدراسة تم تقييم نتائج تلك الطريقة في علاج الناسود الشرجى حدوة الحصان المتشعب فيما يخص الوقت المستغرق في الإجراء

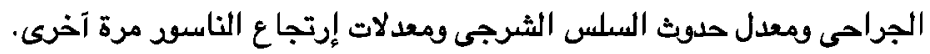

وقد آجريت الدراسة على ·r مريض يعانون من الناسور الشرجى حدوة الحصان والذين تم تشخيصهم بواسطة الفحص الإكلينيكى آى الرنين المغناطيسى.

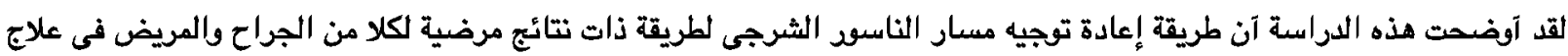

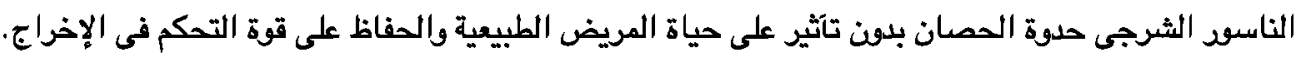

